\title{
Lizard and Newt Tail Regeneration: A Quantitative Study
}

S. A. BARANOWITZ, ${ }^{1.3}$ P. F. A. MADERSON ${ }^{2}$ AND T. G. CONNELLY ${ }^{~}$

${ }^{1}$ Department of Anatomy, University of Michigan, Ann Arbor, Michigan 48109 and

${ }^{2}$ Biology Department, Brooklyn College of City University of New York,

Brooklyn, New York 11210

\begin{abstract}
Almost perfect fits of the Gompertz equation to the growth in length of tail regenerates in the lizard, Lacerta lepida, and the newt, Notophthalmus viridescens, were obtained. Comparison of certain parameters of the equation with published mitotic index data suggests that the Gompertz equation characterizes each system at least from the time that significant mitotic activity is first observed histologically. An objective method for comparing the regeneration periods of the two species is described and applied.

A unified hypothesis derived from consideration of properties of the Gompertz equation successfully accounts for the following phenomena reported, but previously unexplained, in the literature: (1) proximal amputations result in longer regenerates than do distal amputations; (2) proximal amputations elicit greater absolute rates of elongation (in $\mathrm{mm} /$ day) than do distal amputations; (3) the percent replaced of the length removed is rather constant, regardless of the absolute length regenerated; and (4) one of the parameters of the Gompertz equation appears to be lognormally distributed in a regenerating population. (See text for references.)

A computerized interactive graphical system for normalizing growth equations of individual regenerates and integrating the mathematical model with potential candidates for biological control factors is briefly described.
\end{abstract}

Many investigations of regenerative phenomena have been troubled by great variability in both control and experimental populations. Recently, Baranowitz et al. ('77) applied a statistical method to evaluating growth curves of regenerates and outlined techniques for objective comparison of different experimental groups. The present study was designed to determine whether the Gompertz model they utilized would be valuable for comparing tail regeneration in two different species. In addition, we felt that a statistical analysis of this type might shed light on some observations concerning the rate of regeneration which have appeared in the literature (see section $\mathrm{E}$ of DISCUSSION).

Comparison of our data with published mitotic index studies indicates that the Gompertz model characterizes both lizard and newt tail regeneration from the time that sig. nificant mitotic activity is first detected in each system. Studies of the relationships between the parameters of the equation and biological control factors (cellular or macromo- lecular) were facilitated by the development of a computerized interactive graphical system. A hypothesis providing a unified expla. nation for several observations in the literature concerning the rate of regeneration is presented.

\section{MATERIALS AND METHODS \\ (A) Experimental procedures}

\section{Lizards}

Experiments on Lacerta lepida were begun at Brooklyn College in January 1975. The animals were obtained commercially and five of each sex which had not previously regenerated were selected. Their average snout-vent length was $147.2 \pm 10.3 \mathrm{~mm}$. The Coefficient of Variability $(\mathrm{CV}=\mathrm{u} / \mathrm{s} . \mathrm{d} . \times 100)$ was therefore 7.0. Their average weight was $103.8 \pm$ $17.2 \mathrm{gm}(\mathrm{CV}=16.6)$ and average intact tail length was $258.7 \pm 30.6 \mathrm{~mm}(\mathrm{CV}=11.8)$. The distribution of each of these characteristics was not significantly different from normal.

\footnotetext{
${ }^{3}$ Present addresa: New York University School of Medicine, Student Mail, 550 First Avenue, New York, New York 10016.
} 
Animals of both sexes were maintained together in an incubator in wood-framed wire mesh cages. A temperature of $34 \pm 1^{\circ} \mathrm{C}$ and a 12-hour light photoperiod were used. The animals were toe-clipped for identification and were fed crickets, mealworms, and water ad libitum.

Seventy percent of the tail of each animal, by length, was removed by amputation with a razor blade. No growth was observed during the first week post-amputation. From then on, measurements were made with a millimeter ruler every three to four days through the eighth week post-amputation. L. lepida is fairly docile at this temperature, and the tail could readily be straightened for measuring even at later stages. The amputated portion of the tail of each animal was fixed for later measurement of stump area. However, many of the specimens were subsequently found to have been inadequately stored, and therefore analysis of the stump area of the Lacerta tails was not performed.

\section{Newts}

The studies of Notophthalmus viridescens were conducted at the University of Michigan in May 1976 with animals obtained from Bill Lee's Newt Farms in Oak Ridge, Tennessee. Because of the perfection of tail regeneration in this species, it could not be determined whether any of these animals had previously regenerated. The sex of the animals was not recorded. Twenty animals were selected for the experiment, of which five died and one showed no growth and was excluded from the analysis. The 14 remaining animals had an average snout-vent length of $49.4 \pm 2.5 \mathrm{~mm}$ (CV $=5.0$ ), a verage weight of $3.42 \pm 0.85 \mathrm{gm}$ (CV $=24.8$ ) and average intact tail length of 52.1 $\pm 4.9 \mathrm{~mm}(\mathrm{CV}=9.4)$. The distribution of each of these characteristics was not significantly different from normal.

The animals were kept in groups of five in plastic dishes $(18.5 \times 13.0 \times 9.5 \mathrm{~cm})$ filled with dechlorinated tap water. They were fed every two to three days with beef liver and the water was changed after each feeding. The animals were kept in an incubator set to $25 \pm$ $0.5^{\circ} \mathrm{C}$ and 12 -hour light photoperiod. The unique spot pattern of each individual was recorded for identification.

Seventy-five percent of the tail of each animal was removed using a razor blade. (The $75 \%$ level was chosen to permit comparison with the results of Iten and Bryant, '76.) The animals were anesthetized prior to amputation by immersion for 15 to 20 minutes in ethyl-m-aminobenzoate methanesulfonate (Eastman, 1:1,000). Anesthesia was not necessary for making measurements of the regenerate. Measurements were made every two to three days for six weeks using a dissecting microscope with an ocular micrometer. The magnification was changed to accomodate the entire length of the regenerate at later stages. Measurements of the earlier stages were made at the magnification one micrometer unit = $0.05 \mathrm{~mm}$, while measurements for most of the later stages required the magnification one micrometer unit $=0.10 \mathrm{~mm}$. Since one of the statistical assumptions underlying the least square fit technique is that the independent variable (e.g., time) is known precisely, the time of each observation was recorded accu. rate to \pm 10 minutes.

The amputated portion of the tail of each animal was fixed in Bouin's fluid, dehydrated in a series of alcohols, cleared in xylene and embedded in Paraplast. Two of the specimens were accidentally destroyed. It was assumed that the cut edge of the amputated portion would have the same area as the cut edge of the stump. (Due to fixation shrinkage of tissues, this is only relatively true.) The Paraplast block in which each specimen was embedded was trimmed until the cut edge of the tissue was at the surface. The outline of the edge of each specimen was traced at a magnification of $12 \times$ using a camera lucida mounted in a Wild M-5 stereomicroscope. The outline of the entire edge, including the lateral skin flaps was traced. The rationale for this procedure and the problems encountered are outlined in the DISCUSSION.

\section{(B) Mathematical procedures}

A substantial literature exists as to the relative merits of different equations in fitting sigmoid growth curves (Laird et al., '65; Kowalski and Guire, '74). Many equations fit sigmoid growth data about equally well, and it is often not possible to determine which equation is "best" using goodness-of-fit as a criterion. This problem was solved to a large extent by Deakin's demonstration ('70) that, of all possible three-parameter equations available for S-shaped curves, only the Gompertz equation is consistent with the allometric law. Since the fundamental purpose of fitting an equation to growth data of an organ or organism is to elicit the growth dynamics of its con- 
stituent tissues (and ultimately cells), only an equation that is capable of bridging the gap between these different levels of organization is of biological interest. Since only the Gompertz curve possesses this property, it is the three-parameter curve of choice for regeneration studies.

The Gompertz equation has proved exceptionally useful in describing and analysing a wide range of developmental phenomena, including embryonic and postnatal growth of organs and whole organisms (Laird, '65, '66a,b, '67), and about two dozen tumors (see references in Lloyd, '75).

On mathematical grounds, and on the basis of its empirical success in describing developmental systems, the Gompertz curve seems to be the best model for describing the sigmoid growth of a regenerate. In this presentation it will be used primarily in the form:

$$
L=L_{i} \exp \left(\operatorname{sgr}_{i} \cdot \frac{B^{t_{i}}-1}{\ln B}\right)
$$

where " $i$ ", the day of initiation, is defined as the day post-amputation on which the proliferation of cells first follows a Gompertz pattern. (Evidence is presented that day " $i$ " coincides with the day on which significant mitotic activity first occurs.) $\mathrm{L}$ is the length at any time post-initiation $\left(t_{i}\right)$. The parameters of the equations are $L_{i}, \operatorname{sgr}_{i}$, and $B . L_{i}$ is the length on day $\mathrm{i} . \mathrm{Sgr}_{\mathrm{i}}$ is the specific growth rate (1/L)dL/dt on day i. $0<B<1$.

We may define any point on a curve as a percentage $(P)$ of the curve's final asymptote $\left(L_{f}\right)$ so that $\mathrm{P} \equiv \mathrm{L} / \mathrm{L}_{\mathrm{f}}$ and $\mathrm{P}_{\mathrm{i}} \equiv \mathrm{L}_{\mathrm{i}} / \mathrm{L}_{\mathrm{f}}$. The normalized growth velocity, $\mathrm{dP} / \mathrm{dt}$, is

$$
\mathrm{dP} / \mathrm{dt}=(-1 \mathrm{nB})(\mathrm{P})(-1 \mathrm{nP})
$$

(Baranowitz et al., '77). Since $P_{i}$ is also equal to $\exp \left(\mathrm{sgr}_{\mathrm{i}} / 1 \mathrm{nB}\right)$, equation (1) may also be written:

$$
L=L_{i} P_{i}^{\left(B^{\left.t_{i}-1\right)}\right.}
$$

A program for fitting Gompertz curves to tumor growth data was graciously provided by Dr. H. H. Lloyd of the Southern Research Institute and was extensively modified to accommodate regeneration data. The final program was named GARD (Gompertz Analysis of Regeneration Dynamics). The algorithm used is that reported by Simpson-Herren and Lloyd ('70) and it was unchanged for our application. In our notation, their description of the algorithm may be paraphrased as follows. If we let $\alpha=-1 \mathrm{nB}$, then equation (1) may be rewritten as $1 \mathrm{~nL}=1 \mathrm{~nL}_{\mathrm{i}}+\left(\mathrm{sgr}_{\mathrm{i}} / \alpha\right)\left(1-\mathrm{e}^{-\alpha \mathrm{ti}}\right)$. This can be expressed as $u=a_{0}+a_{1} v$ where $u$ $=\operatorname{lnL}, \mathrm{a}_{0}=1 \mathrm{~nL}_{\mathrm{i}}+\operatorname{sgr}_{\mathrm{i}} / \alpha, \mathrm{a}_{1}=-\operatorname{sgr}_{\mathrm{i}} / \alpha$, and $\mathrm{v}=\mathrm{e}^{-\alpha t i}$. The parameters $\mathrm{a}_{0}$ and $\mathrm{a}_{1}$ are evaluated by the method of least squares for each estimate of $\alpha$, starting with $\alpha=0.1$. The value of $\alpha$ is then systematically modified until the variance about the straight line converges to a minimum. Upon convergence, the best $\alpha$ is known, $\operatorname{sgr}_{\mathrm{i}}=-\alpha \mathrm{a}_{1}$, and $\mathrm{L}_{\mathrm{i}}=\exp \left(\mathrm{a}_{0}+\mathrm{a}_{1}\right)$. In this work, the time of the first observation was set as the zero point for each animal, and to standardize the regression parameters for all animals, the parameters of the equations were extrapolated back to the time of amputation.

We adopted Ricklefs' ('67) suggestion that data less than $10 \%$ of the initially computed upper asymptote not be included in the final regression, since it was empirically observed that data below $10 \%$ of the computed asymptote often approximated a straight line. Not only does edema occur at the onset of regeneration but measuring extremely small structures approaches the limits of experimental error. Since most of the upper asymptotes of the lizards were between 70 and $90 \mathrm{~mm}$, data less than $7 \mathrm{~mm}$ were not used. Since most of the upper asymptotes computed for the newt tails were about $20 \mathrm{~mm}$, data less than $2 \mathrm{~mm}$ were not used.

Laird ('65, '66a) and Simpson-Herren and Lloyd ('70) used weighted least squares. We empirically determined that to obtain good fits it was necessary to weight the least squares so that the larger observed lengths (i.e., the later observations) were given more importance. The lizard data required the third power while the newt data required the fourth power. This empirical weighting procedure produced excellent fits (RESULTS), and a rationale is presented in the APPENDIX.

A graph was produced for each regenerate incorporating both the observed points and the regression line (figs. 1,3 ). In addition to this visual evaluation of the fit, the program computed a coefficient of multiple correlation, $R$. The use of $R$ provides an estimate of the goodness of fit about the untransformed (sig. moid) data. $0<\mathrm{R}<1$, with 1 indicating a perfect fit.

To attempt to relate the parameters of the equation (especially $L_{i}$ ) to biological control factors, a computer program named GIG (Gompertz Interactive Graphics) was written. The program was developed with the following biological considerations in mind. Mitotic index studies and theoretical concerns indicate that proliferation of cells following a 
Gompertz pattern does not occur immediately post-amputation, but rather some time in the first week or so after amputation (DISCUSSION). It would seem that the field of cells initiating proliferation (e.g., $L_{i}$ ) is somewhere between 10 and 100 cells measured linearly (Wolpert, '69). Therefore, two types of axis translations (see below) were devised to determine whether a normalization could be found in which the number of cells predicted for each regenerate and the time at which that number of cells was present coincided with what theoretical (Wolpert, '69) concerns and mitotic index studies (see DISCUSSION for references) indicate.

One translation was simply to choose a day post-amputation during the first week or two in which the $L_{i}$ predicted for each animal was in the range of $0.1-1.0 \mathrm{~mm}$ (i.e., for convenience, we assumed an average cell diameter of $10 \mu=0.01 \mathrm{~mm}$ ).

A second translation was to choose a $P$ value such that (1) the range of $L_{i}$ was between 0.1 and $1.0 \mathrm{~mm}$, and (2) the times at which these $\mathrm{L}_{\mathrm{i}}$ 's were present were in a small range of days during the first week of regeneration-coinciding with what mitotic index studies indicate for lizards and newts (DISCUSSION).

The GIG program permits axis translations indicated by the user to be performed on the curves of individual animals (or all animals in an experiment), and provides an immediate display of the parameters of the equation utilizing the new origin for each curve. One can then view the superimposed curves of chosen animals for each translation on a graphics terminal (e.g., Tektronix 4010). The integral (length vs. time), differential (dL/dt vs. time), and normalized graphs can thus be immediately analyzed for each translation. Listings of the GARD and GIG programs are available upon request.

Computations of descriptive statistics (e.g., mean and s.d.), correlation statistics between animals' characteristics and equation parameters, and a test for normality were performed using the MIDAS statistical package of the University of Michigan Statistical Research Laboratory.

Merrell ('31) has shown that there are a number of different ways of obtaining means of growth curves. The method of averaging the lengths of each animal at each observation time is the least satisfactory. Obtaining the means of each parameter of the equation for

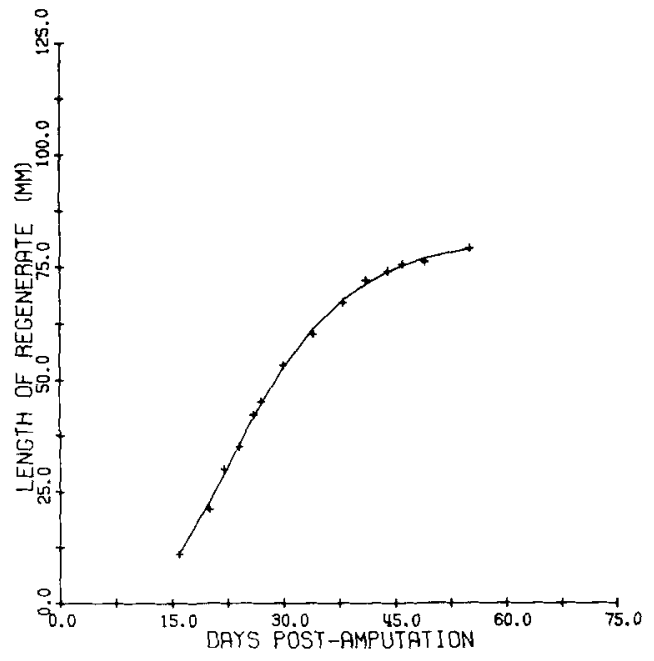

Fig. 1 Growth of an individual $L$. lepida tail regenerate. Crosses are observed data points. Solid line is regression line of the Gompertz equation.

each curve, and using those means in a "meanconstant" curve is substantially better, and is the method utilized herein for the "mean" lizard and "mean" newt curves. Merrell applied a third method involving Taylor series expansions for averaging any type of growth curve. We are presently trying to adapt her general formulae to the Gompertz curve. However, since Merrell indicated that the "meanconstant" curve differed very little from the true "mean" curve obtained by her formulae for the sigmoid logistic curve, we here use the mean-constant curve for convenience.

\section{RESULTS}

\section{(A) Lacerta lepida}

Excellent fits of Gompertz curves to the $L$. lepida tail regeneration data were obtained. For each animal, $R>0.99$. The curve for an individual animal is shown in figure 1. Figs. 2a-c show the range of variation in the population. The numerical information from the regressions is summarized in table 1 .

Parameter B showed very little variation $(\mathrm{CV}=1.5)$. Since the length of the regeneration period is determined by B (DISCUSSION), this showed little variation in the length of the regeneration period for different individuals. To elucidate this, the day on which the mean curve reached $\mathrm{P}=0.95$ was computed. On the fifty-third day post-amputation, $8 / 10$ animals had a $P$ in the range $0.90-1.00$ and $2 /$ 
TABLE 1

L. lepida tail regeneration summary $\left(70 \%\right.$ amputation; $\left.34 \pm 1^{\circ} \mathrm{C}\right)$

\begin{tabular}{|c|c|c|c|c|c|}
\hline & & & Mean & S.D. & C.V. \\
\hline \multirow[t]{3}{*}{ (I) } & $\begin{array}{l}\text { Basic data } \\
\text { B }\end{array}$ & $\begin{array}{l}\text { Parameter governing length } \\
\text { of regeneration period }\end{array}$ & 0.89688 & 0.013670 & 1.5 \\
\hline & $\mathbf{L}_{\mathbf{f}}$ & $\begin{array}{l}\text { Predicted final asymptotic } \\
\text { length }\end{array}$ & $89.1 \mathrm{~mm}$ & $13.0 \mathrm{~mm}$ & 14.6 \\
\hline & $\begin{array}{l}\text { Percent } \\
\text { replaced }\end{array}$ & 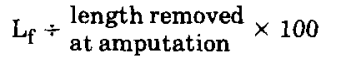 & $49.3 \%$ & $5.2 \%$ & 10.6 \\
\hline \multirow[t]{3}{*}{ (II) } & \multicolumn{5}{|c|}{$\begin{array}{l}\text { Axis translation: Day of initiation }(i) \\
\text { for each regenerate is the day post- } \\
\text { amputation on which } P=0.002\end{array}$} \\
\hline & $\mathrm{i}$ & $\begin{array}{l}\text { Day on which initiation of } \\
\text { Gompertzian proliferation } \\
\text { occurs }\end{array}$ & 8.08 & 2.95 & 36.7 \\
\hline & $\mathrm{L}_{\mathrm{i}}$ & Length at initiation & $0.178 \mathrm{~mm}$ & $0.026 \mathrm{~mm}$ & 14.6 \\
\hline \multirow[t]{6}{*}{ (III) } & $\begin{array}{l}\text { Axis transl } \\
\text { for each re } \\
\text { amputation }\end{array}$ & $\begin{array}{l}\text { ay of initiation (i) } \\
\text { is day } 10 \text { post. }\end{array}$ & & & \\
\hline & $\mathrm{L}_{\mathrm{i}}$ & Length at initiation & $1.14 \mathrm{~mm}$ & 1.31 & 111.5 \\
\hline & $\mathbf{k}_{1}$ & $\begin{array}{l}\text { Coefficients in } \\
\text { regression equation }\end{array}$ & 0.74744 & & \\
\hline & $\mathrm{k}_{2}$ & $\mathbf{s g r}_{i}=\mathbf{k}_{1}+\mathbf{k}_{2} L_{i}+k_{3} L_{i}^{2}$ & -0.27955 & & \\
\hline & $\mathbf{k}_{3}$ & & 0.044729 & & \\
\hline & $R_{\mathrm{ggr}_{\mathrm{i}}} \cdot \mathrm{L}_{\mathrm{i}}$ & $\begin{array}{l}\text { Coefficient of multiple } \\
\text { correlation between } \\
\mathrm{sgr}_{\mathrm{i}} \text { and } \mathrm{L}_{\mathrm{i}}\end{array}$ & 0.90211 & & \\
\hline
\end{tabular}

10 animals had a $\mathrm{P}$ in the range $0.80-0.90$. Thus most animals had reached $90 \%$ or more of their final asymptote about the same time.

The two types of translations described in MATERIALS AND METHODS were attempted. The second type of translation, using the value $P$ $=0.002$, was most successful (table 1 and figs. $2 d-f)$. The range of days post-amputation for day " $i$ " is close to the time which mitotic index studies indicate that mitotic activity starts in those lizard species in which mitotic counts have been made (see DISCUSSION for references). The range of $L_{i}$ was also within the theoretical range predicted (MATERIALS AND METHODS). As shown in figures $2 e$, $f$ the peaks of $\mathrm{dL} / \mathrm{dt}$ and of $\mathrm{dP} / \mathrm{dt}$ respectively occurred within a small time range.

The first type of translation, using the value $\mathrm{i}=10$ days post-amputation, was also of interest. Although the mean $\mathrm{L}_{\mathrm{i}}$ was $1.14 \mathrm{~mm}$ here, the range of $\mathrm{L}_{\mathrm{i}}$ 's was unrealistically large $(0.03-4.3 \mathrm{~mm})$. Yet, of the values tried for this type of translation, day 10 was found to be about the best. Thus, this type of axis translation seems less biologically meaningful than the type of translation in which day " $\mathrm{i}$ " for each individual regenerate is set to the day on which a chosen $P$ value is attained. However, in another respect, this sort of translation was of use. We wished to test for correlation among the parameters of the equation $\left(L_{i}\right.$, $\mathrm{sgr}_{\mathrm{i}}$, and $\mathrm{B}$ ). One of the assumptions underlying the test for correlation we used is that the distribution of each parameter is not significantly different from normal. When the parameters were extrapolated back to time zero = amputation $\left(\mathrm{L}_{\mathrm{a}}, \mathrm{sgr}_{\mathrm{a}}\right.$, and $\mathrm{B}$ : the form in which the parameters are listed by the GARD program), the distributions of $\mathrm{L}_{\mathrm{a}}$ and $\operatorname{sgr}_{\mathrm{a}}$ were each found to be skewed. Translation to day 10 provided unskewed parameters $\mathrm{L}_{\mathrm{i}}$ and $\mathrm{sgr}_{\mathrm{i}}$, then permitting correlation tests. $L_{i}$ and sgr $_{i}$ were found to be highly correlated (table 1). Parameter B was found to be uncorrelated with either $L_{i}$ or $s g r_{i}$. No a priori reason for the parabolic nature of the correlation between $\mathrm{L}_{\mathrm{i}}$ and $\mathrm{sgr}_{\mathrm{i}}$ could be discerned (DISCUSSION).

\section{(B) Notophthalmus viridescens}

For each of the $N$. viridescens regressions, $\mathrm{R}$ $\geqslant 0.98$. There appeared to be slightly more variability in the shapes of the curves and the 
TABLE 2

\begin{tabular}{|c|c|c|c|c|c|}
\hline & & & Mean & S.D. & c.V. \\
\hline \multirow[t]{4}{*}{ (I) } & $\begin{array}{l}\text { Basic data } \\
\mathrm{B}\end{array}$ & $\begin{array}{l}\text { Parameter governing length } \\
\text { of regeneration period }\end{array}$ & 0.93080 & 0.024311 & 2.6 \\
\hline & $\mathrm{L}_{\mathrm{f}}$ & $\begin{array}{l}\text { Predicted final asymptotic } \\
\text { length }\end{array}$ & $14.4 \mathrm{~mm}$ & $3.3 \mathrm{~mm}$ & 23.0 \\
\hline & $\begin{array}{l}\text { Percent } \\
\text { replaced }\end{array}$ & 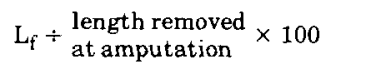 & $36.7 \%$ & $7.8 \%$ & 21.2 \\
\hline & Stump area & See MATERIALS AND METHODS & $9.9 \mathrm{~mm}^{2}$ & $2.9 \mathrm{~mm}^{2}$ & 29.2 \\
\hline \multirow[t]{3}{*}{ (II) } & $\begin{array}{l}\text { Axis translati } \\
\text { for each regen } \\
\text { amputation or }\end{array}$ & $\begin{array}{l}\text { Day of initiation (i) } \\
\text { is the day post- } \\
\text { ich } P=0.030\end{array}$ & & & \\
\hline & $\mathrm{i}$ & $\begin{array}{l}\text { Day on which initiation of } \\
\text { Gompertzian proliferation } \\
\text { occurs }\end{array}$ & 5.93 & 3.51 & 59.2 \\
\hline & $\mathrm{L}_{\mathrm{i}}$ & Length at initiation & $0.432 \mathrm{~mm}$ & $0.099 \mathrm{~mm}$ & 21.4 \\
\hline \multicolumn{6}{|c|}{$\begin{array}{l}\text { (III) Axis translation: Day of initiation (i) } \\
\text { for each regenerate is day } 8 \text { post- } \\
\text { amputation }\end{array}$} \\
\hline & $\mathrm{L}_{\mathrm{i}}$ & Length at initiation & $0.666 \mathrm{~mm}$ & $0.389 \mathrm{~mm}$ & 58.4 \\
\hline & $\mathbf{k}_{1}$ & $\begin{array}{l}\text { Coefficients in } \\
\text { regression equation: }\end{array}$ & 0.67568 & & \\
\hline & $\mathrm{k}_{2}$ & $\operatorname{sgr}_{\mathrm{i}}=\mathbf{k}_{1}+\mathbf{k}_{2} \mathrm{~L}_{\mathrm{i}}+\mathbf{k}_{3} \mathrm{~L}_{\mathrm{i}}^{2}$ & -1.1257 & & \\
\hline & $\mathrm{k}_{3}$ & & 0.56590 & & \\
\hline & $\mathbf{R}_{\mathrm{sgr}_{\mathrm{i}} \cdot L_{\mathbf{i}}}$ & $\begin{array}{l}\text { Coefficient of multiple } \\
\text { correlation between } \\
\mathrm{sgr}_{\mathrm{i}} \text { and } \mathrm{L}_{\mathrm{i}}\end{array}$ & 0.92410 & & \\
\hline & $\mathrm{k}_{1}^{\prime}$ & $\begin{array}{l}\text { Coefficients in } \\
\text { regression equation: }\end{array}$ & 0.87910 & & \\
\hline & $\begin{array}{l}\mathrm{k}_{2}^{\prime} \\
\mathrm{k}_{3}^{\prime}\end{array}$ & $\mathrm{B}=\mathrm{k}^{\prime}{ }_{1}+\mathrm{k}^{\prime}{ }_{2} \mathrm{~L}_{\mathrm{i}}+\mathrm{k}^{\prime}{ }_{3} \mathrm{~L}_{\mathrm{i}}{ }^{2}$ & $\begin{array}{c}0.14717 \\
-0.079344\end{array}$ & & \\
\hline & $\mathrm{R}_{\mathrm{B} \cdot \mathrm{L}_{\mathrm{i}}}$ & $\begin{array}{l}\text { Coefficient of multiple } \\
\text { correlation between } \\
B \text { and } L_{i}\end{array}$ & 0.79717 & & \\
\hline
\end{tabular}

scatter around the fitted lines in the newts than for the lizards (fig. 3). The range of variation in final length, $\mathrm{dL} / \mathrm{dt}$, and $\mathrm{dP} / \mathrm{dt}$ is shown in figures $4 \mathrm{a}-\mathrm{c}$.

The mean $\mathrm{B}$ obtained was different from that of the Lacerta, and its CV was about 1.7 times as great as the mean B for the Lacerta (table 2). Since parameter B determines the length of the regeneration period (e.g., the time for a regenerate to reach a given $P$ value), different newts reached a given $P$ at a range of times post-amputation. The day on which the mean curve reached $P=0.95$ was computed to be day 65 . On this day $9 / 14$ animals $(64 \%)$ had P's in the range $0.90-1.00,3 / 14$ animals $(21 \%)$ had P's in the range $0.80-0.90$, $1 / 14(7 \%)$ at $0.70-0.80$, and $1 / 14(7 \%)$ at 0.60 0.70 .

The translation $P=0.030$ provided a range of $\mathrm{L}_{\mathrm{i}}$ and $\mathrm{i}$ which appeared reasonable on the basis of mitotic index studies (DISCUSSION).

The translation $i=8$ days post-amputation was useful for correlation tests (table 2). $\mathrm{L}_{\mathrm{i}}$ and $\operatorname{sgr}_{\mathrm{i}}$ were highly correlated. $\mathrm{L}_{\mathrm{i}}$ and $\mathrm{B}$ were also found to be correlated. The stump area was significantly correlated to $\mathrm{L}_{\mathrm{i}}$ at almost the 0.05 level $(0.06>p>0.05)$. Because of methodological problems in obtaining the stump area (DISCUSSION), the import of this result is very difficult to assess.

Fig. 2 Tail regeneration in $L$. Lepida at $34 \pm 1^{\circ} \mathrm{C}$ after amputation of $70 \%$ of the original tails. The symbols only identify different regression lines and do not represent data points. The square marks the mean curve for all ten animals in the experiment. The other four curves are the regressions for individual animals chosen to demonstrate the variability in the population. (a) and (d) are integral plots, (b) and (e) are differential plots, and (c) and (f) are normalized differential plots (see text for normalization equation). For plots (d) (f), the origin for each curve was set to the time when a chosen $P_{i}$ value was at. tained. 

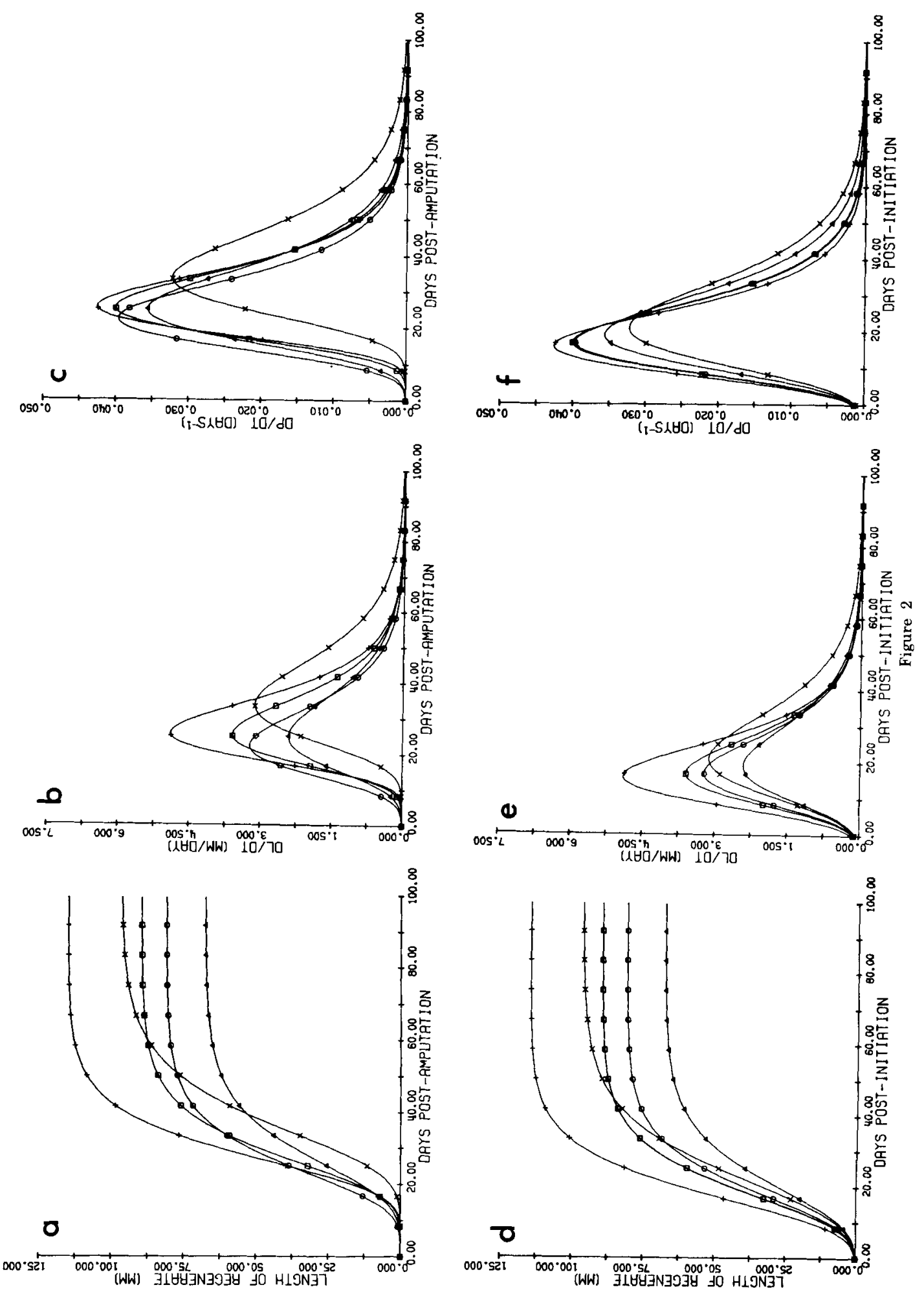

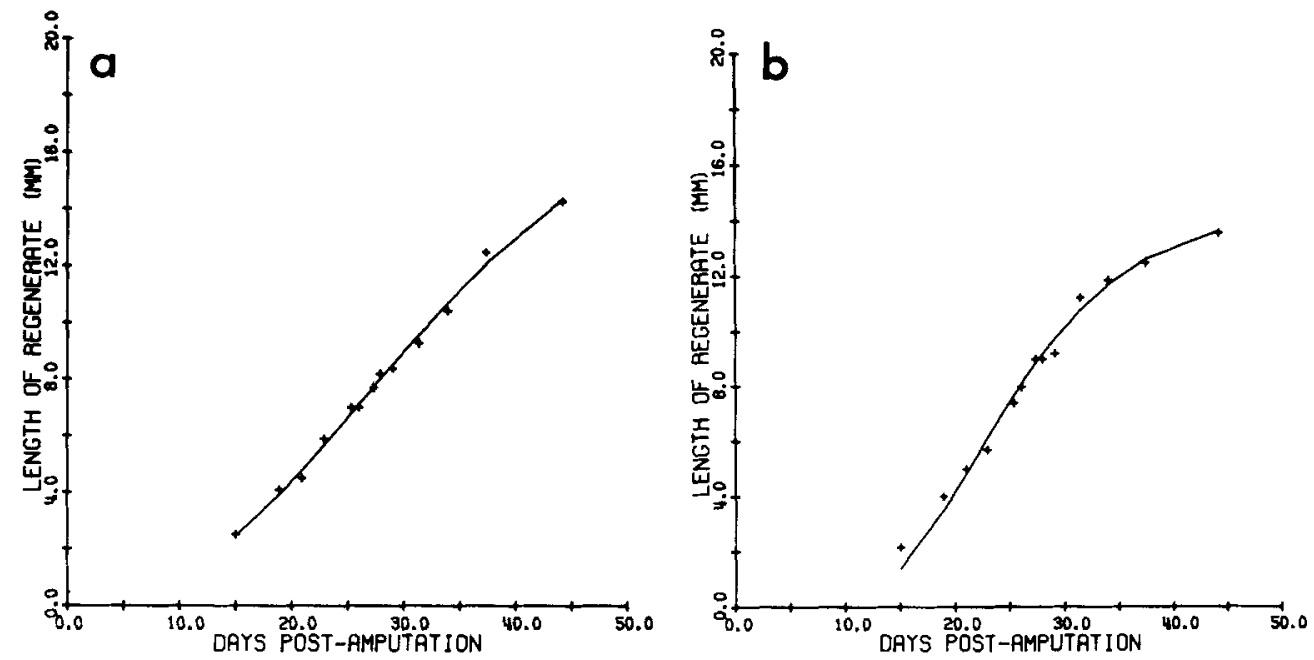

Fig. 3 Growth of two individual $N$. viridescens tail regenerates. Note that one of the regenerates had not yet started to level off when the last observation was made. Crosses are observed data points. Solid lines are regression lines of the Gompertz equation.

\section{DISCUSSION}

\section{(A) Computer programs}

The empirical success of the Gompertz equation in fitting regeneration data is not surprising because of its success in fitting an exceptional range of other developmental phenomena. The GIG program was eminently convenient for translating and normalizing the curves of large numbers of animals, and it provided numerical and graphical information in a rapid and easily analyzable manner. It facilitated preliminary association of equation parameters with biological factors and enabled easy comparison of the regeneration process in different species.

Our procedure for weighting the least squares was essentially empirical. A justification of weighting at least to the second power is presented in the APPENDIX, but the theoretical basis of using higher (e.g., third or fourth) powers remains obscure. One way we hope to approach this problem in the future is to devise formulae for confidence intervals for the parameters of the regression, and to see whether weighting to the third or fourth power results in parameter confidence intervals which are much different from those obtained when weighting to the second power. If there is little change in the confidence intervals with higher powers, then perhaps it would be best to weight data using the second power, because its theoretical basis is better understood.

\section{(B) Biological meaning of equation parameters}

(1) " $i$ " - The day on which Gompertzian proliferation dynamics are initiated

While it has been demonstrated that most of the regeneration period is well described by Gompertzian proliferation dynamics (Baranowitz et al., '77), it is of interest to determine how early this pattern characterizes the regenerate. The problem is schematized in figure 5 and while specific information is not yet available, some hints may be gleaned from the literature.

Two of the classic landmarks of the regeneration process are: (1) the appearance on the stump of a grossly visible mound of mesenchymatous cells (see review by Carlson, '74), and (2) the onset of grossly visible exponential elongation of the mound a few days after it has first appeared. Regression analysis of regenerate growth has thus far incorporated measurements beginning with the onset

Fig. 4 Tail regeneration in $N$. viridescens at $25 \pm$ $0.5^{\circ} \mathrm{C}$ after amputation of $75 \%$ of the original tail. The symbols only identify different regression lines and do not represent data points. The square marks the mean curve for all 14 animals in the experiment. The other four curves are the regressions for individual animals chosen to demonstrate the variability in the population. (a) and (d) are integral plots, (b) and (e) are differential plots, and (c) and (f) are normalized differential plots (see text for normalization equation). For plots (d)-(f), the origin for each curve was set to the time when a chosen $P_{i}$ value was attained. 

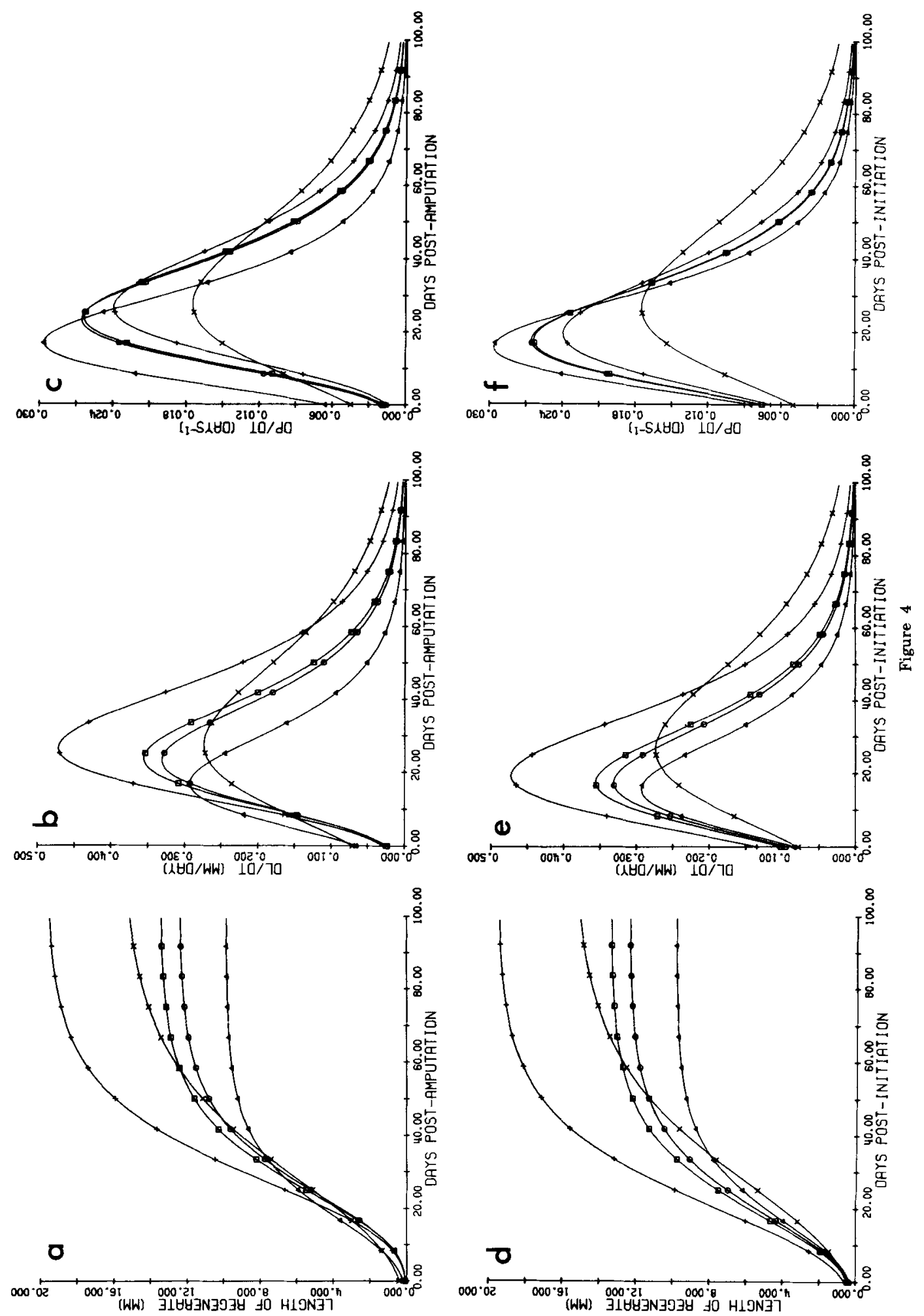


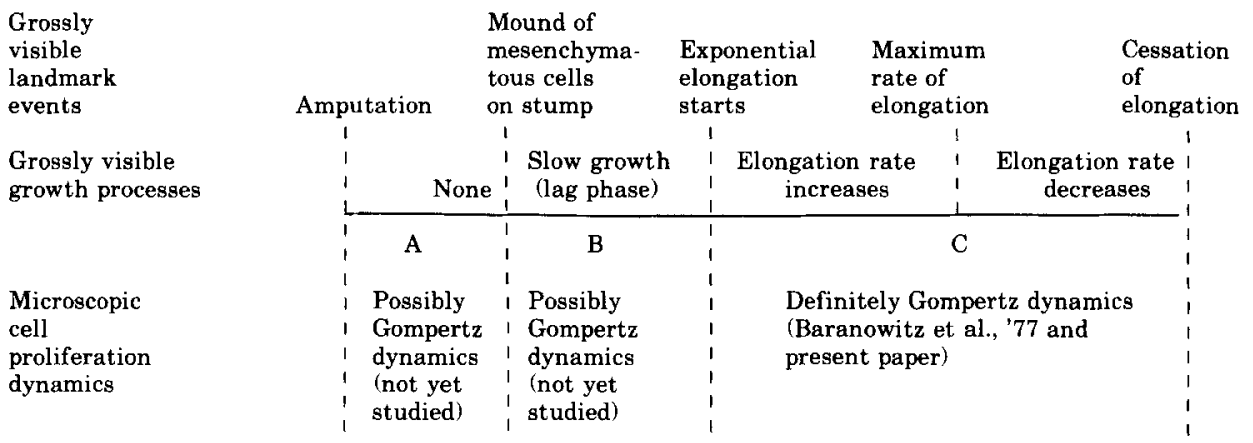

Fig. 5 Schematic design of the problem in identifying day " $i$ ", the day on which proliferation of cells first follows a Gompertz pattern.

of grossly visible exponential growth. Regression analysis of absolute numbers of cells in the mound from the time it first becomes grossly visible until gross exponential elongation starts (period " $B$ " in fig. 5) has not yet been done. However, there are reports in the literature that the mitotic index shows a continuous, gradual increase from the first time mitotic figures are visible in the stump (Kelly and Tassava, '73; Tassava et al., '74; Mescher and Tassava, '75), and then it levels off. This suggests the possibility that Gompertzian dynamics characterize the growth of the regenerate at least from the time the mound is first grossly visible.

The externally visible mound of mesenchymatous cells arises by (1) migration and (2) proliferation of dedifferentiated cells near the amputation plane (see review, Carlson, '74). We would also wish to know whether the proliferation by dedifferentiated cells in the stump, which results in the formation of the mound (period " $A$ " in fig. 5), also follows Gompertzian dynamics. The pattern of mitotic index mentioned above suggests that Gompertzian dynamics may describe the regenerate from the very first appearance of mitosis in the stump, and through subsequent phases. Since information is now lacking as to how early such dynamics characterize the regenerate, we have of necessity defined "i" as that (as yet unknown) day post-amputation on which the proliferation of cells first follows a Gompertz pattern. " $t_{i}$ " is then defined as time post-initiation, (see fig. 6).

Radioautographic studies (Simpson, '65; Cox, '69; Kelly and Tassava, '73; Tassava et al., '74; Mescher and Tassava, '75) indicate that in a given species kept under standardized conditions, mitosis begins in most ani- mals at approximately the same time post-amputation. Thus " $i$ " seems to be about the same for all animals in a given population under standardized conditions.

\section{(2) " $L_{i}$ "-Length when Gompertzian proliferation is initiated}

The question of the minimum number of cells required to start proliferation, e.g., the size of $\mathrm{L}_{\mathrm{i}}$, is interesting. Wolpert ('69) comments: ". . . most embryonic fields seem to involve distances of less than 100 cells . . ." (referring to linear distances). Grobstein and Zwilling ('53) suggest that there is a minimum "critical mass" of cells necessary to initiate any developmental event. Thus it seems reasonable to assume that the field of cells initiating regeneration is between 10 and 100 cells measured linearly.

The existence of a range of $L_{i}$ 's within a population is not inconsistent with the assumption presented below that $P_{i}$ is constant. Since $\mathrm{P}_{\mathrm{i}}=\mathrm{L}_{\mathrm{i}} / \mathrm{L}_{\mathrm{f}}$, it is only the ratio $\left(\mathrm{P}_{\mathrm{i}}\right)$ that we expect to be constant. Using the assumptions presented in this section (e.g., $i, t_{i}, P_{i}$, and $B$ constant for all animals under standardized conditions), if one animal has a larger $\mathrm{L}_{\mathrm{j}}$ (a larger number of cells initiating proliferation), it will have a larger $\mathrm{L}_{\mathrm{f}}$ (a larger regenerate length).

However, it is clear that the use of linear measurements carries an inherent danger in extrapolation. For instance, if an average cell diameter is assumed to be $10 \mu$, and $\mathrm{L}_{\mathrm{i}}=100$ $\mu$, one could not estimate the actual number of cells to be ten, since that would presuppose that the cells are stacked one on top of another. The three-dimensional arrangement of cells in the early regenerate is presently unknown. However, it does seem probable (in 


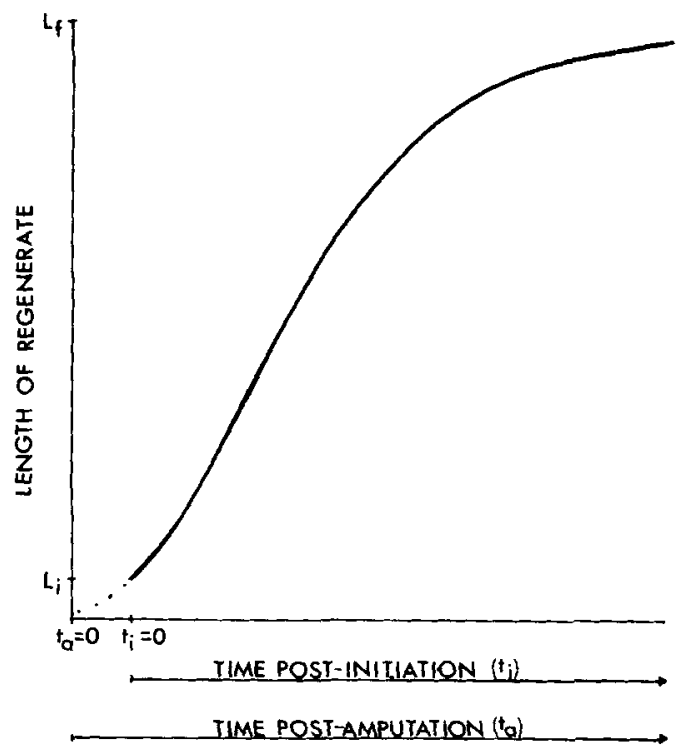

Fig. 6 Translation of the origin of a Gompertz curve. Terms are defined in the text (p. 19).

analogy to reasoning of Laird, '64) that comparison of the $L_{i}$ 's of different animals provides some general indication of the relative numbers of cells initiating Gompertzian proliferation.

(3) Comparison of " $i$ " and " $L_{i}$ " with histological studies of mitotic index

Mitotic activity is said to start about seven to eight days post-amputation in lizard tail regeneration (Lygosoma laterale, Simpson, '65) and five to six days post-amputation in amphibians (Rana pipiens tail, Bieber and Hitchings, '59; $N$. viridescens limb, Mescher and Tassava, '75; Ambystoma mexicanum limb, Kelly and Tassava, '73; Tassava et al., '74).

We were successful with the axis translation setting the time of initiation to the day post-amputation on which each animal reached a uniform $P$ value such that: (1) the range of $L_{i}$ was between 0.1 and $1.0 \mathrm{~mm}$, and (2) the times at which these $L_{i}^{\prime}$ 's were present coincided as much as possible with the days post-amputation which mitotic index studies indicate that mitotic activity starts. We obtained a mean of 8.1 days for L. lepida and 5.9 days for $N$. viridescens tail regeneration.

Unfortunately, the literature does not, to our knowledge, document the amount of individual variation in (1) the day on which mitosis starts, (2) the number of cells at that time, or (3) changes in the preceding at different temperatures. Thus, we cannot determine presently whether the range of variation in day of initiation and number of cells at that time, which we obtained using this $P$ normalization, represents a realistic degree of variability. In any case, utilizing presently available data, it does seem that the Gompertz function characterizes the growth of the regenerate from the first day which various studies indicate that significant mitotic activity starts.

An empirical correlation between $\mathrm{L}_{\mathrm{i}}$ (representing the number of cells at initiation) and $\operatorname{sgr}_{i}$ (the specific growth rate at initiation) was found in both the lizard and the newt system. This relationship seems reasonable on both mathematical and biological grounds. Mathematically, the relationship between sgr and $L$ at any time is $\mathrm{sgr}=(1 / \mathrm{L}) \mathrm{dL} / \mathrm{dt}$, and we see no reason why this relation should not hold at the inception of the curve. Biologically, it seems reasonable that the initial specific growth rate should be determined by the number of cells initiating mitotic activity. Since the parameter $\mathrm{sgr}_{\mathrm{i}}$ is a function of the parameters $L_{i}$ and $B$, it seems that the two major factors controlling regenerate growth are represented by parameters $L_{i}$ and $B$. It is interest. ing that in the lizard, $L_{i}$ and $B$ appear to be uncorrelated yet in the newt, $\mathrm{L}_{\mathrm{i}}$ and $\mathrm{B}$ appear to be correlated. Additional research is clearly necessary.

The correlation we obtained between $\mathrm{L}_{\mathrm{i}}$ and stump area of newt tails must be considered (and criticized) in the light of our methods for measuring the stump area. The relative contributions of skin, bone, muscle, and other tissues to the formation of a mound of mesenchymous, pluripotent cells is as yet only poorly understood (Carlson, '74). Therefore, instead of measuring the area of the whole stump as we did, perhaps if future workers measure the areas of individual tissues in the stump (e.g., connective tissue, bone, muscle) and test each for correlation with $\mathrm{L}_{\mathrm{i}}$, a clearer relationship may emerge. A possible relationship between final regenerate length and stump area has been controversial in the literature for some time (see DISCUSSION, section E). At this time we can only present our results such as they are, and indicate that more work will be required to determine definitely whether there is some relationship between the initiation of regeneration and stump area. 
(4) Comments on " $B$ " and " $P$ "

Parameter $B$ appears to be practically constant for a given species under standardized conditions (Baranowitz et al., '77; RESULTS above). As demonstrated in the next section, $P_{i}$ has little effect on the regeneration period length even when ranging over several orders of magnitude, so it can be considered constant for a given species under standardized conditions.

\section{(C) Definition of the regeneration period}

The regeneration period for different species has not been clearly defined in the literature. A more precise definition of it may be derived from the Gompertz function (equation 3).

The length of the regeneration period is not influenced strongly by $\mathrm{P}_{\mathrm{i}}$, but it is crucially defined by parameter $B$. For instance, consider a range of four orders of magnitude for $P_{i}, 10^{-2}$ to $10^{-6}$. Let $B=0.90$ and $t_{i}=50$ days. Then, when $P_{i}=10^{-2}, P=0.98$, and when $P=10^{-6}$, $P=0.93$. Even with so great a range for $P_{i}$, regeneration is nearly complete by 50 days postamputation. Now consider the effect of $B$. Let $P_{i}=10^{-2}$ and $t_{i}=50$ days. Then when $B=$ $0.95, \mathrm{P}=0.70$, when $\mathrm{B}=0.93, \mathrm{P}=0.88$, and when $\mathrm{B}=0.90, \mathrm{P}=0.98$.

Since the Gompertz curve is asymptotic at both ends there is no mathematical a priori definition of an end boundary for the regeneration process, although one could choose some arbitrary value such as $P=0.95$ for comparative purposes. However, this type of analysis has important implications for assessing the information on regeneration periods now available in the literature, because to the experimenter, the end of regeneration would be the time at which the structure is no longer visibly elongating, that is when $\mathrm{dL} / \mathrm{dt}$ appears to be zero.

If we assume that for a given population under standarized conditions $i, t_{i}, P_{i}$, and $B$ are constant for all animals (section $B$ ), then we would expect $P$ to be the same for all animals at any given time post-initiation $\left(t_{\mathrm{i}}\right)$. The normalized growth velocity would also be the same at any $t_{j}$, since

$$
\frac{\mathrm{dP}}{\mathrm{dt}}=(-\ln \mathrm{B})(\mathrm{P})(-1 \mathrm{n} \mathrm{P})
$$

(Baranowitz et al., '77). The elongation in $\mathrm{mm} /$ day, however, may be different, since $\mathrm{dL} /$ $\mathrm{dt}=\mathrm{L}_{\mathrm{f}} \cdot \mathrm{dP} / \mathrm{dt}$, which may also be written as:

$$
\frac{d L}{d t}=L_{i} \cdot P_{i}-1 \cdot \frac{d P}{d t}
$$

Since $P$ at initiation $\left(P_{i}\right)$ and the normalized growth velocity $(\mathrm{dP} / \mathrm{dt})$ are constant for each animal at each time post-initiation $\left(t_{i}\right)$, the length at initiation $\left(\mathrm{L}_{\mathrm{i}}\right)$ determines the absolute growth velocity in $\mathrm{mm} /$ day $(\mathrm{dL} / \mathrm{dt})$ at any time post-initiation $\left(t_{i}\right)$.

Let us choose some numbers to illustrate the implications for experimental work. Assume $B=0.90, P_{i}=0.01$, and that an average cell diameter is $10 \mu=0.01 \mathrm{~mm}$. Bearing in mind the inherent limitations of estimating numbers of cells utilizing length measurements (see above, p. 26), for the present, consider length measurements as though they really represented absolute numbers of cells. Although the absolute numbers of cells result. ing from our calculations will not be correct, the relative proportions will probably be similar regardless of the true three-dimensional arrangement of cells in the field initiating proliferation. Let $L_{i}$ for animal $I$ to be $0.3 \mathrm{~mm}$ (e.g., about 30 cells) and $L_{i}$ for animal II to be $1.0 \mathrm{~mm}$ (e.g., about 100 cells). Since $\mathrm{L}_{\mathrm{f}}=\mathrm{L}_{\mathrm{i}} / \mathrm{P}_{\mathrm{i}}$, animal I would have a final regenerate length of $30 \mathrm{~mm}$, while animal II would have a final regenerate length of $100 \mathrm{~mm}$.

The lengths that these hypothetical regenerating structures would attain are shown in figure 7a, while the normalized curve is shown in figure $7 \mathrm{~b}$. Due to the exponential nature of the curve, an initial difference of just $0.7 \mathrm{~mm}$ results in a considerable difference in final regenerate length.

The difference in absolute rates of elongation ( $\mathrm{mm} /$ day) is also quite dramatic (see fig. $7 \mathrm{c}$ and normalized fig. 7d). Note however that the maximum absolute rate of elongation $(\mathrm{dL} /$ $\mathrm{dt}$ ) occurs at the same time post-initiation $\left(\mathrm{t}_{\mathrm{i}}\right)$ for both animals. This high point occurs at $P$ $=1 / \mathrm{e}=0.368$ (Winsor, '32). For animal I the greatest rate is $1.16 \mathrm{~mm} /$ day while for animal II the greatest rate is $3.88 \mathrm{~mm} /$ day. Again, this major difference is due to an initial linear difference of only $0.7 \mathrm{~mm}$ (e.g., about 70 cells).

In the seventh week post-amputation (days 43-49), toward the end of regeneration, animal I shows an elongation of $0.83 \mathrm{~mm}$ while animal II shows an elongation of $2.76 \mathrm{~mm}$. In the next (eighth) week post-amputation (days 5056), animal I elongates $0.40 \mathrm{~mm}$ while animal II elongates $1.35 \mathrm{~mm}$. Since rather large structures are being measured, assume that we are using a millimeter rule with a conservative margin of error of $\pm 0.5 \mathrm{~mm}$. To an observer, the termination of regeneration would be defined as the time at which a change of less than $0.5 \mathrm{~mm} /$ week (the margin of error) oc- 

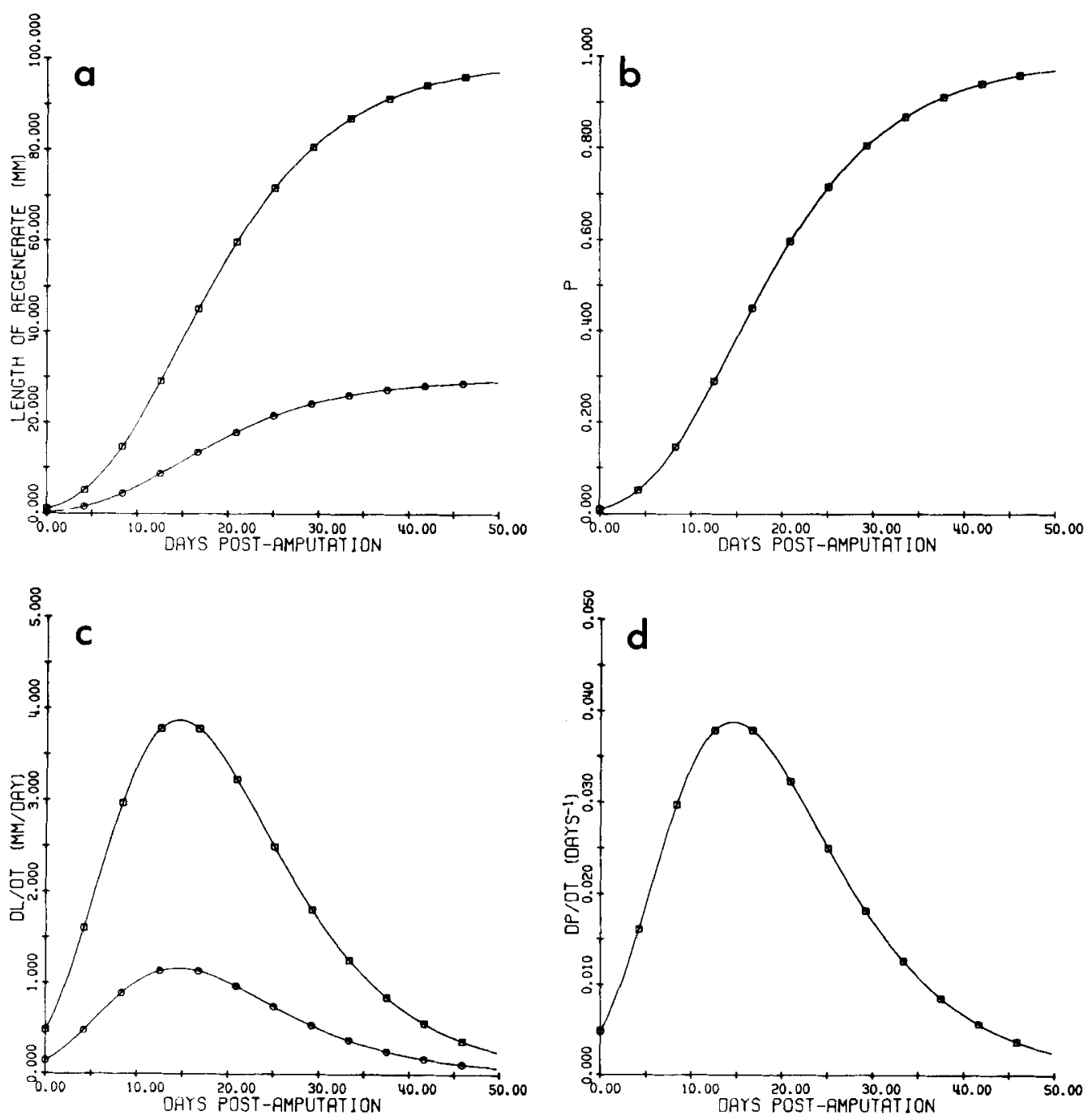

Fig. 7 Observed and normalized growth curves for two hypothetical regenerating structures defined by the conditions specified in section $E$ of DISCUSSION. $O=$ animal I; $\square=$ animal II. (a) and (c) represent the types of curves an experimenter would obtain by plotting his daily observations. (b) and (d) represent normalized curves, in which the curves of animals $\mathrm{I}$ and II are found to be superimposed. See text for normalization equations.

curs. Therefore, at week 8 , animal I will appear to the experimenter to have terminated regeneration, while animal II would seem to still be regenerating. Actually, both animals are at the same normalized stage $(P)$ in regeneration. It would not be until week 10 that animal II would appear to have stopped regenerating.

The termination of regeneration from the experimenter's viewpoint is of necessity defined by the smallest $\mathrm{dL} / \mathrm{dt}$ that can be measured. We must therefore understand that the times of termination of regeneration reported in the literature were arrived at this manner. Yet, from a normalized viewpoint, all animals reach the same proportion $(P)$ of their final length $\left(\mathrm{L}_{\mathrm{f}}\right)$, that proportion being determined by $B$ and $P_{i}$, at the same time post-initiation. Should we wish to define the end of regeneration as a given $P$ value (e.g., $P=0.95$ ), then all animals terminate at the same time postinitiation.

The initiation of regeneration is difficult to determine precisely from measurements 
alone, due to the problems of measuring small structures (e.g., $1 \mathrm{~mm}$ long) near the error margin (e.g., $\pm 0.5 \mathrm{~mm}$ ) of the measuring instrument.

For these reasons, in executing regression analysis using a Gompertz function, it would probably be best to utilize data points in the range of $P=0.10$ to $P=0.90$. This is also suggested (for a variety of reasons) by Ricklefs ('67).

\section{(D) Comparison of regeneration periods}

Parameter $\mathrm{B}$ is the primary factor determining the length of the regeneration period and the normalized growth velocity (see above). Objective comparison of species is thus facilitated by comparison of their mean B's ( $\overline{\mathrm{B}}$ 's).

Under the environmental and amputation conditions specified, the regeneration period of $N$. viridescens is longer than that of $L$. lepida. For instance, the "mean" newt reaches $\mathrm{P}=0.9512$ days later than the "mean" lizard (fig. 8c). This is because the normalized growth velocity of $N$. viridescens is lower than that of L. lepida (figs. 8d,e.)

However, we must immediately point out that really identifying intrinsic differences between regeneration systems requires that we also take into account: (1) the temperature at which experiments are conducted, (2) the percent of the intact structure amputated, and (3) the homogeneity of the population with respect to age and size.

The temperature at which experiments are conducted has been shown to be crucial to the rate of regeneration (Cox, '69; Maderson and Licht, '68; Maderson and Salthe, '71). Since the newt and lizard experiments were conducted at $25^{\circ} \mathrm{C}$ and $34^{\circ} \mathrm{C}$ respectively (e.g., at what seem to be the optimum comfortable temperature for each species), it remains to be determined whether the differences in $\bar{B}$ are due to the temperature difference of the experiments. To ascertain intrinsic species differences, it will be necessary to accumulate data at a range of temperatures for each species.

The percent amputated here was almost the same in the two species, and it is unlikely that the small difference made a significant contribution to the difference in $\overline{\mathrm{B}}$. As with temperature, it will be necessary to obtain data at several different percent amputations for each species before identifying intrinsic species differences. The possible influence of the ages of the animals on $B$ is a very difficult problem. Although historically the snout-vent length and body weight of the animals have been used as indications of age, this relationship may, of course, only be generally true. We are at present unable to draw conclusions as to the intrinsic differences between the lizards $L$. lepida and A. carolinensis (Baranowitz et al., '77) primarily because different amputation regimes were used. For the Anolis study, absolute amounts were removed, rather than percentages of intact tails. Although our newt results are similar to those obtained by Iten and Bryant ('76) for 75\% amputation and $25^{\circ} \mathrm{C}$, our average $L_{f}$ was slightly higher than that which they obtained.

\section{(E) A unified hypothesis for four regeneration puzzles}

Use of the analytical methods in this paper has led to a potential unified explanation for the following four observations reported in the literature:

(1) Proximal amputations result in longer regenerates than do distal amputations (tadpole tail: Ellis, '09; newt limb: Iten and Bryant, '73; newt tail: Iten and Bryant, '76).

(2) Proximal amputations elicit greater absolute rates of elongation (in $\mathrm{mm} /$ day) than do distal amputations (see references in Iten and Bryant, '73).

(3) The percent regenerated of the length removed is rather constant, regardless of the absolute length regenerated (tadpole tail: Ellis, '09; lizard tail: Tassava and Goss, '66; Bryant and Bellairs, '67; Maderson and Licht, '68; present paper; newt tail: present paper; fish fins: Tassava and Goss, '66).

(4) The parameter " $\mathrm{P}_{\mathrm{a}}$ " of the Gompertz equation (A3) appears to be logonormally distributed in a regenerating population (Baranowitz et al., '77).

The model detailed below states that under standard experimental conditions, most of the parameters governing regenerating are relatively constant in a population, while the number of cells in the field which initiates proliferation is the factor primarily responsible for the above four phenomena reported in the literature.

We start with a simple hypothetical system defined by a set of postulates, and demonstrate that this system possesses the four characteristics mentioned in the literature. Some of the postulates in the model are derived from past experimental studies, while 

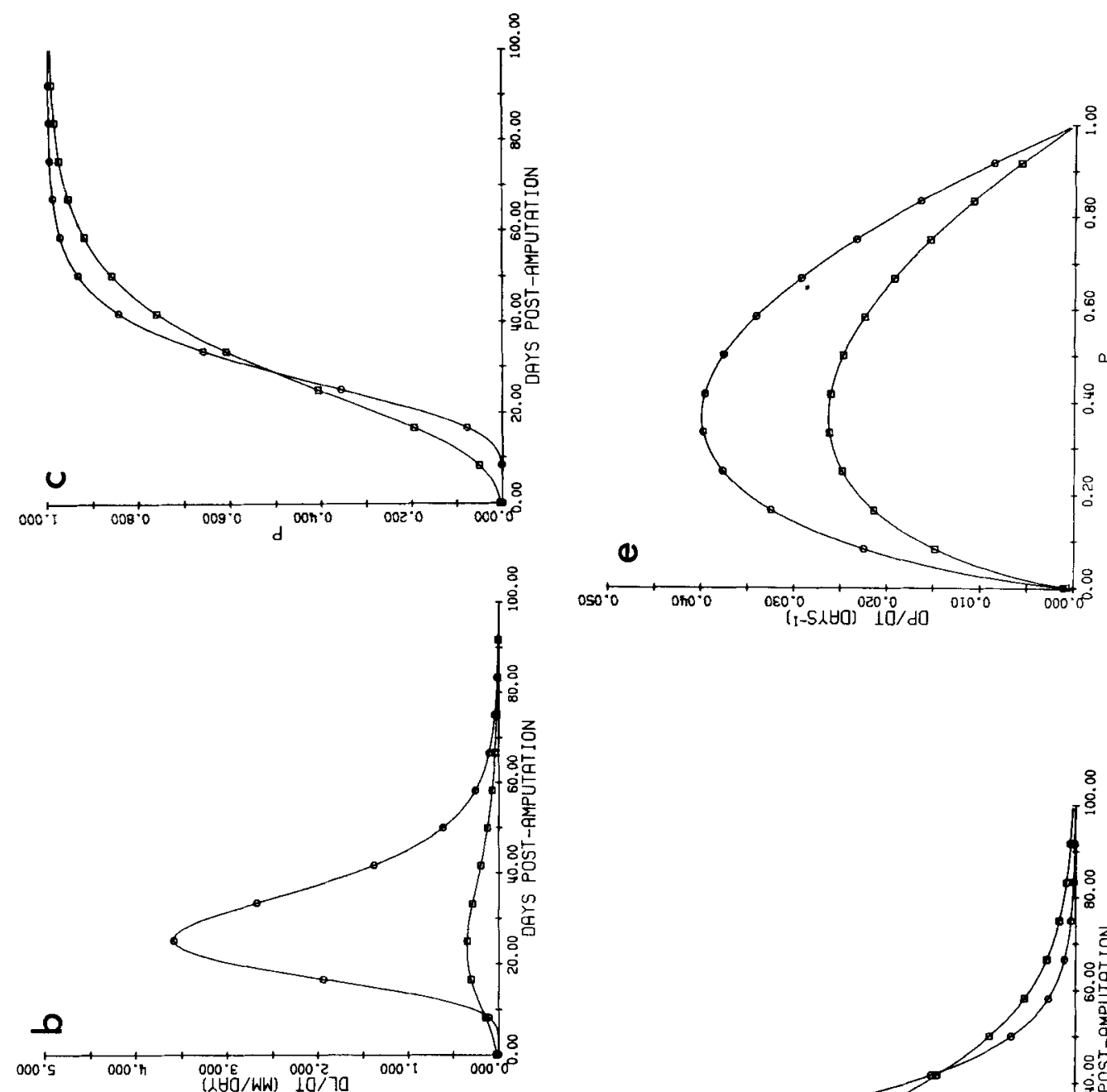

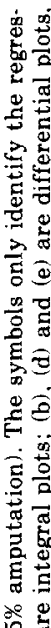

资

ن의

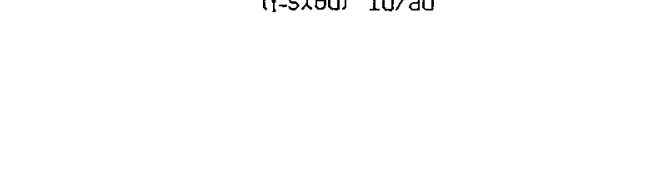

跑

赵

范

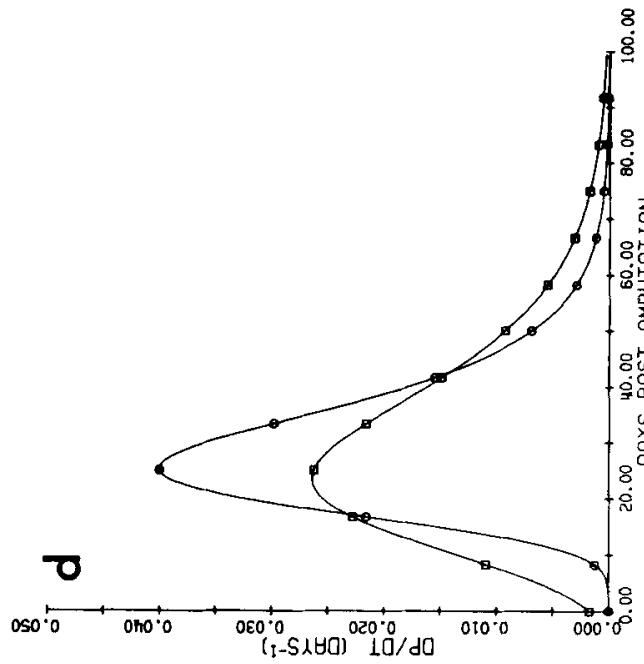

之节

T.

$\overline{\mathrm{E}}$

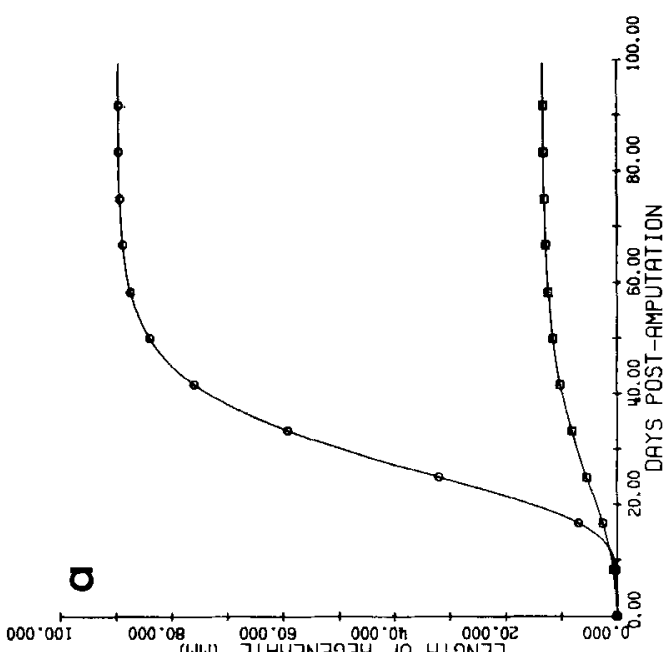


others are included merely to simplify the initial presentation, which is intended only as a first approximation of the real situation. For instance, it is clear that if some variation is present (as is probably true) in some of the parameters we postulate as being constant (on the basis of the data reviewed in section $B$ ), then this might explain some of the variability in the four above phenomena reported in the literature.

The hypothetical system is that of a tail in the shape of a right circular cone which is capable of regeneration. The postulates are: (a) Regeneration from any level follows the Gompertz curve for length, $L=L_{i} P_{i}{ }^{\left(B^{t i}-1\right)}$. (b) $i, t_{i}, P_{i}$ and $B$ are approximately constant for all animals in the population and are unaffected by level of amputation (section B). (c) The number of cells initiating proliferation $\left(\mathrm{L}_{\mathrm{i}}\right)$ is proportional to the radius of the stump remaining after amputation: (N.B. This postulate in particular is presented in a highly oversimplified manner and is modified and discussed in detail later.) (d) All animals in the population have original tails with the same terminal angle. (e) None of the animals in the population has previously regenerated. (f) The population is maintained at a constant temperature. (g) All physiological factors (e.g., age, phase of breeding cycle, nutritional state, etc.) are the same for all animals.

We will now investigate the implications of these statements for regeneration of individual animals, with respect to observations (1) and (2) listed above. Although the restriction imposed by postulate (e) makes it impossible to test the above two observations on individuals, these conditions have been inferred from studies of populations (Iten and Bryant, '73, '76) (fig. 9).

\section{Effect of level of amputation on final length of regenerate}

Since $L_{\mathrm{f}}=\mathrm{L}_{\mathrm{i}} / \mathrm{P}_{\mathrm{i}}$ and $\mathrm{P}_{\mathrm{i}}$ is assumed to be constant (postulate $b$ ), the length of the final structure is directly dependent on the number of cells initiating regeneration $\left(L_{i}\right)$. The number of cells initiating regeneration is proportional to the stump radius (postulate c), which in a cone increases proximally. More proximal amputation will therefore lead to a greater number of cells initiating regeneration and a larger final structure. As demonstrated in section $\mathrm{C}$, a small difference in $\mathrm{L}_{i}$ can make a huge difference in the final length of the regenerate.

\section{Effect of level of amputation on rate of elongation of regenerate}

The normalized growth velocity $(\mathrm{dP} / \mathrm{dt})$ under these conditions ( $P$ and $B$ constant) will be constant regardless of the level of amputation (note postulate $\mathrm{b}$ ). The absolute rate of elongation $\left(\mathrm{dL} / \mathrm{dt}\right.$ ) is equal to $\mathrm{L}_{\mathrm{i}} \cdot \mathrm{P}_{\mathrm{i}}^{-1} \cdot \mathrm{dP} / \mathrm{dt}$ (APPEN. DIX). Since $P_{i}$ is also constant (postulate $b$ ), the number of cells initiating regeneration $\left(\mathrm{L}_{\mathrm{i}}\right)$ is the ultimate factor that determines the rate of elongation at any time. Since $L_{i}$ increases proximally, as explained in the preceding paragraph, more proximal amputations result in greater absolute rates of elongation (dL/dt).

Having dealt with the implications of this theoretical system for regeneration of individuals, let us now consider the implications for a population of regenerating animals in light of observations (3) and (4) listed above.

\section{Constant percent replacement}

As explained in paragraph (I) above, the final length is directly dependent on the number of cells initiating regeneration $\left(L_{i}\right)$. If we remove a constant percent of the tail of each animal (e.g., 50\%), animals with greater lengths removed will have larger stump radii (postulate d). This would result in greater number of cells initiating proliferation in animals with greater lengths removed (postulate c) and, therefore, longer final regenerates. Thus a proportionality between amount removed and amount regenerated would be maintained. The precise value of the percentage replaced on the length removed is determined by the magnitudes of $B$ and $P_{i}$.

\section{Lognormal distribution of $P_{a}$}

To give observation (4) somewhat more biological meaning, let us use the translation presented in the APPENDIX to restate the observation as " $P_{i}$ appears to be lognormally distributed."

$P_{\mathrm{i}}=\operatorname{Exp}\left(\mathrm{sgr}_{\mathrm{i}} / 1 \mathrm{nB}\right)$, where $\operatorname{sgr}_{\mathrm{i}}$ is the specific growth rate $(\mathrm{sgr}=(1 / \mathrm{L}) \mathrm{dL} / \mathrm{dt})$ at the time of initiation. Stating that $P_{i}$ appears to be lognormally distributed is the same as saying that $\left(\mathrm{sgr}_{\mathrm{i}} / \mathrm{nB}\right)$ appears to be normally distributed. Since B is constant (postulate b), it is $\mathrm{sgr}_{j}$ which seems to be normally distributed.

We have found empirically that $\mathrm{sgr}_{\mathrm{i}}$ is highly correlated with $\mathrm{L}_{\mathrm{i}}$ (RESULTS) by the formula: $\mathrm{sgr}_{\mathrm{i}}=\mathrm{K}_{1}+\mathrm{K}_{2} \mathrm{~L}_{\mathrm{i}}+\mathrm{K}_{3} \mathrm{~L}_{\mathrm{i}}{ }^{2}$. Since $\mathrm{sgr}=$ $(1 / \mathrm{L}) \mathrm{dL} / \mathrm{dt}$, a correlation between $\mathrm{L}_{\mathrm{i}}$ and $\mathrm{sgr}_{\mathrm{i}}$ is to be expected. Intuitively, it is reasonable to 


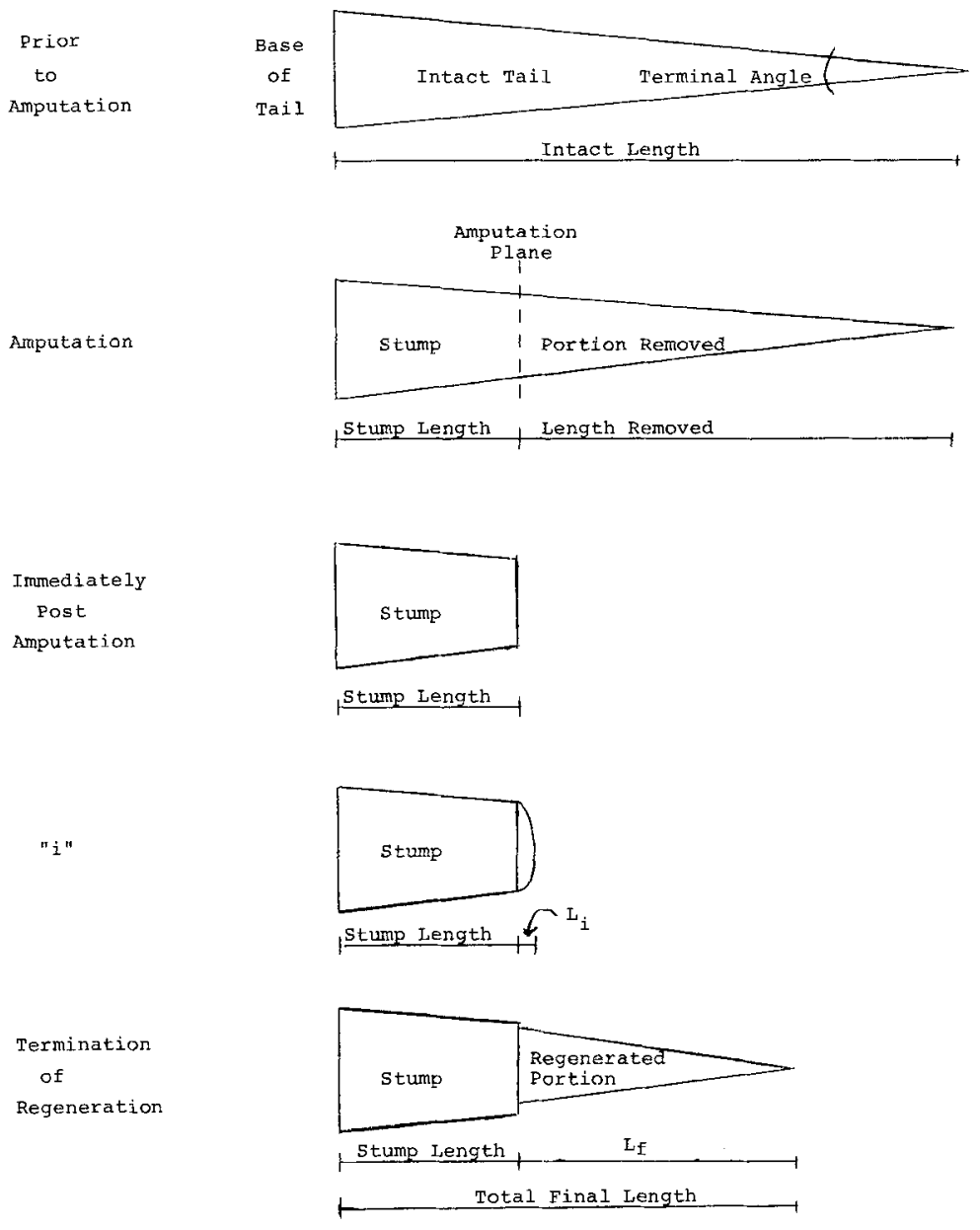

Fig. 9 Schematic diagram illustrating some of the terms used in the text. " $i$ " is the day on which Gompertz pattern proliferation is first initiated. $L_{\mathrm{i}}$ is the length of the developmental field on day "i" (see text). $L_{f}$ is the final length of the regenerated portion.

expect that the initial specific growth rate is determined by the initial number of cells present.

Since $\operatorname{sgr}_{\mathrm{i}}$ is correlated with $\mathrm{L}_{\mathrm{i}}$, let us examine more closely how our experimental regime determines $L_{i}$. In amputating a standard percentage of each animal's tail (MATERIALS AND METHODS) or a standard number of millimeters behind the vent (Maderson and Salthe, '71), we cut off different absolute lengths of tail, resulting in different stump radii. In reality, for both of these situations, the results are randomly chosen stump radii and thus, random distribution of $L_{i}$ (note postulate c). Since $\mathbf{s g r}_{i}$ is merely a function of $L_{i}$, the observed normal distribution of $\mathbf{s g r}_{i}$, with its associated lognor- mal distributions of $P_{a}$ and $P_{i}$, is quite reasonable and follows directly from our experimental procedure.

Let us now examine postulate c more closely. Tassava and Goss ('66) studied the effect of stump radius on rate of degeneration in the Anolis tail, which tapers greatly, and the gourami (Trichogaster sp.) fin, which tapers only slightly. It was concluded that no relationship between stump radius and either the length of the regenerate or the rate of regeneration was apparent in either species. We wish to suggest that reexamination of the data they present in the light of information acquired in the decade following their report alters that interpretation of their results. 
Let us first address their data on fish fins. The average intact fin length was $40 \mathrm{~mm}$, and the experiments were conducted at a constant temperature of $25 \pm 1^{\circ} \mathrm{C}$. The animals were divided into three groups, in which $75 \%, 50 \%$, and $25 \%$ respectively of the intact fin length was removed. $100 \%$ of the length removed was regenerated in each group (e.g., $10 \mathrm{~mm}$ regenerated at $25 \%$ removal, $20 \mathrm{~mm}$ at $50 \%$ removal, $30 \mathrm{~mm}$ at $75 \%$ removal). The mean "diameters" of the stump for each group were reported as the average of the long and short axes of the stump. If we halve the reported mean "diameters" we obtain "radii" of 0.140 , $0.115,0.090 \mathrm{~mm}$ for the $75 \%, 50 \%$, and $25 \%$ removal groups respectively. The authors concluded, quite reasonably at that time, that the small differences in mean stump diameter could not be held responsible for the differences in rate of regeneration and final regenerate length for the different groups.

However, we demonstrate in this paper (section C) that due to the exponential nature of the Gompertz function governing regeneration, small differences in stump radius may be so magnified by the exponential growth process that great differences in final regenerate lengths are observed. Given that knowledge, the data presented by Tassava and Goss actually tends to support the thesis that the final length and rate of regeneration are, at least to some extent, dependent on stump radius. Since their results are presented in a clear and objective manner, we may reexamine them a decade later in the light of newly available information.

It has been since been demonstrated (Cox, '69; Maderson and Licht, '68; Maderson and Salthe, '71) that temperature is a crucial factor in the rate of lizard tail regeneration, and a range of only $4^{\circ} \mathrm{C}$, such as that utilized by Tassava and Goss, may introduce a very large element of variability into the system. Since the effect of temperature on rate of lacertilian regeneration was not adequately known at that time, it is in no way a criticism of these authors' 1966 methods. However, this additional variable in their study precludes our reexamining their data for lizards, as we have for fish fins. We do feel that their experiment should be repeated with newer controls, and that their earlier conclusion that stump radius has no effect should be held in abeyance until such studies are done.

Actually, stump radius might be expected to show some relationship with final length of the regenerate only if two conditions are met. The first condition involves the cell types (as yet inadequately identified), which actually dedifferentiate and accumulate into a mound. If the amounts of those tissues decrease with decreasing stump radius, then stump radius would be expected to show some relationship with $\left(\mathrm{L}_{\mathrm{i}}\right.$, and thus) $\mathrm{L}_{\mathrm{f}}$, the final regenerate length. The second condition involves those factors which influence the processes involved in blastema formation. Such processes may include wound healing, debris removal, dedifferentiation, proiliferation of dedifferentiated cells to contribute to the mound, and migration of dedifferentiated cells to the mound. If those influencing factors also decrease distally with stump radius, then stump radius and final regenerate length would be expected to show some relationship.

Although we found some statistical correlation between newt tail stump area and $\mathrm{L}_{\mathrm{i}}$, methodological problems in measurement prohibit us from concluding that any definitive relationship between the two can be inferred from our study, and further investigations are necessary.

To summarize, despite indications to the contrary in the literature, the possible role of stump radius in determining final regenerate length has not yet been adequately investigated using appropriately rigid experimental conditions and statistical methodology. We feel that this relationship must remain an open question pending further study.

However, it is clear that whether the model stands or falls is not primarily dependent on postulate $\mathrm{c}$ as initially stated. The crucial point is the existence of a proximodistal gradient of factors which are responsible for determining the magnitude of $L_{\mathrm{i}}$. As mentioned above, these factors might be the number of cells which are actually capable of dedifferentiating and/or other tissues which influence the processes involved in blastema formation. As we have indicated above, the factors responsible for blastema formation are, as yet, inadequately identified.

\section{ACKNOWLEDGMENTS}

This work was supported by NIH Grants HD08150, CA 18622, NS 13924-01A1 and NIH Training Grant 5-T01-GM00312. The authors are most grateful to Dr. Harris H. Lloyd of the Kettering-Meyer Laboratory, Southern Re- 
search Institute, Birmingham, Alabama for providing a listing of a program for fitting tumor growth data to the Gompertz equation. That program had been developed under Contract N01-CM4-3756, Division of Cancer Treatment, National Cancer Institute, NIH, Department of HEW. We wish to especially thank Mr. James Knox of the University of Michigan Computing Center for extensively modifying the tumor growth program to fit regeneration data (as the GARD program), and Mr. Edward Fronczak of the University of Michigan Computing Center for harnessing sophisticated integrated graphics programs to our needs in the GIG program. We are grateful to Mr. Robert Kushler of the University of Michigan Statistical Research Laboratory for providing statistical consultation through the course of this project. The authors would like to express thanks to Dr. Bruce M. Carlson, Dr. Stanley N. Salthe and Mr. Robert Kushler for critical review of earlier drafts of this paper, and to Ms. Julia Norris and Ms. Elizabeth Ashcraft for technical assistance. Una Maderson kindly typed the manuscript.

\section{LITERATURE CITED}

Baranowitz, S. A., S. N. Salthe and P. F. A. Maderson 1977 The use of the Gompertz curve in an analysis of the dynamics of lizard tail regeneration. J. Theor. Biol., 65: 267-279.

Bieber, S., and G. H. Hitchings 1959 Effects of growth-inhibitors on amphibian tail blastema. Cancer Research, 19: $112-115$.

Bryant, S. V., and A. d'A. Bellairs 1967 Tail regeneration in the lizards Anguis fragilis and Lacerta dugesii. J. Linn. Soc. (Zool.), 46: 297-305.

Carlson, B. M. 1974 Factors controlling the initiation and cessation of early events in the regenerative process. In: Neoplasia and Cell Differentiation. G. V. Sherbet, ed. S. Karger, Basel, pp. 60-105.

Cox, P. G. 1969 Some aspects of tail regeneration in the lizard, Anolis carolinensis. II. A description based on histology and autoradiography. J. Exp. Zool., 171: 127-150.

Deakin, M. A. B. 1970 Gompertz curves, allometry, and embryogenesis. Bull. Math. Biophysics, 32: 445-452.

Ellis, M. M. 1909 The relation of the amount of tail regenerated to the amount removed in tadpoles of Rana clamitans. J. Exp. Zool., 7: 421-455.

Grobstein, C., and E. Zwilling 1953 Modification of growth and differentiation of chorio-allantoic grafts of chick blastoderm pieces after cultivation at a glass-clot interface. J. Exp. Zool., 122: 259-284.

Iten, L. E., and S. V. Bryant 1973 Forelimb regeneration from different levels of amputation in the newt, Notoph. thalmus viridescens: length rate and stages. Wilhelm Roux' Archiv., 173: 263-282.

- 1976 Regeneration from different levels along the tail of the newt, Notophthalmus viridescens. J. Exp. Zool., 196: 293-306.

Kelly, D. J., and R. A. Tassava 1973 Cell division and ribonucleic acid synthesis during the initiation of limb regen- eration in larval axolotls (Ambystoma mexicanum). J. Exp. Zool., 185: 45-54.

Kowalski, C. J., and K. E. Guire 1974 Longitudinal data analysis. Growth, 38: 131-169.

Laird, A. K. 1964 Dynamics of tumor growth. Brit. J. Cancer, 18: 490-502.

1965 Dynamics of relative growth. Growth, 29: 249-263.

1966a Development of embryonic growth. Growth, 30: 263-275.

1966b Postnatal growth of birds and mammals. Growth, 30: 349-363.

1967 Evolution of the human growth curve. Growth, 31: 345-355.

Laird, A. K., S. A. Tyler and A. D. Barton 1965 Dynamics of normal growth. Growth, 29: 233-248.

Lloyd, H. H. 1975 Estimation of tumor cell kill from Gompertz growth curves. Cancer Chemother. Rep., 59: 267.277.

Maderson, P. F. A., and P. Licht 1968 Factors influencing rates of tail regeneration in the lizard Anolis carolinensis. Experientia, 24: 1083-1086.

Maderson, P. F. A., and S. N. Salthe 1971 Further observations on tail regeneration in Anolis carolinensis (Iguanidae, Lacertilia). J. Exp. Zool., 177: 185-190.

Merrell, M. 1931 The relationship of individual growth to average growth. Human Biology, 3: 37-70.

Mescher, A. L., and R. A. Tassava 1975 Denervation effects on DNA replication and mitosis during initiation of limb regeneration in adult newts. Dev. Biol., 44: 187-197.

Ricklefs, R. E. 1967 A graphical method of fitting equations to growth curves. Ecology, 48: 978-983.

Simpson, S. B., Jr. 1965 Regeneration of the lizard tail In: Regeneration in Animals and Related Problems. V. Kiortsis and H. A. L. Tampuschs, eds. North-Holland Publishing Co., Amsterdam, pp. 431-443.

Simpson-Herren, L., and H. H. Lloyd 1970 Kinetic parameters and growth curves for experimental tumor systems. Cancer Chemother. Rep., 54: 143-174.

Tassava, R. A., L. L. Bennett and G. D. Zitnik 1974 DNA synthesis without mitosis in amputated denervated forelimbs of larval axolotls. J. Exp. Zool., 190: 111-116.

Tassava, R. A., and R. J. Goss 1966 Regeneration rate and amputation level in fish fins and lizard tails. Growth, 30 : 9-21.

Winsor, C. P. 1932 The Gompertz curve as a growth curve. Proc. Nat. Acad. Sci., 18:1-8.

Wolpert, L. 1969 Positional information and the spacial pattern of cellular differentiation. J. Theor. Biol., 25: $1-47$.

\section{APPENDIX}

\section{(A) Derivation of mathematical equations}

We start with the classical Gompertz equation

$$
\mathbf{L}(\mathbf{t})=\mathbf{L}_{\mathbf{f}} \mathbf{A}^{\left(B^{t}\right)}
$$

$L(t)$ is the length of the regenerate at any time post-amputation, $t$, measured in days. $L_{f}$ is the asymptotic final length. $A$ and $B$ are constants. $\mathrm{L}_{\mathrm{f}}, \mathrm{A}>0,0<\mathrm{B}<1$. Note that $L(t) \rightarrow L_{f}$ as to $\rightarrow \infty$. In exponential form, (A1) is equivalent to

$$
L(t)=L_{f} \exp (1 n A \cdot \exp (t \ln B))
$$

Specify amputation time as " $a$ ". Let $P_{a}$ re- 
place $A$ in $(A 1)$ and define $P(t) \equiv L(t) / L_{f}$. Then (A1) implies $P(t)=P_{a}{ }^{\left(B^{t}\right)}$

Let $\mathrm{L}_{\mathrm{a}} \equiv \mathrm{L}_{\mathrm{f}} \mathrm{P}_{\mathrm{a}}$. Then (A3) and this definition imply

or

$$
L(t) / L_{f}=P_{a}\left(B^{t}\right)
$$

$$
L(t)=L_{a} P_{a}\left(B^{t}-1\right)
$$

Now let " $\mathrm{i}$ " be the day of initiation and define $t_{\mathrm{i}} \equiv \mathrm{t}-\mathrm{i}$. Thus $\mathrm{t}_{\mathrm{i}}=0$ can be thought of as the new origin. Equation (A3) implies

This motivates defining

$$
P(t)=P_{a}{ }^{\left(B^{\left(t_{i}+i\right)}\right)}=\left(P_{a^{B}}{ }^{\left.B^{i}\right)\left(B^{t_{i}}\right)}\right.
$$

From (A4),

$$
\mathrm{P}_{\mathrm{i}} \equiv \mathrm{P}_{\mathrm{a}}\left(\mathrm{B}^{\mathrm{i}}\right)
$$

$$
\mathrm{L}_{\mathrm{i}} \equiv \mathrm{L}_{\mathrm{a}} \mathrm{P}_{\mathrm{a}}\left(\mathrm{B}^{\mathrm{i}-1)},\right.
$$

where $L_{i}$ is the length at $i$ days post-amputation. Now

$$
\begin{gathered}
L(t)=L_{i} P_{i}^{\left(B^{t-i}-1\right)}=\left(L_{a} P_{a} B^{i}-1\right)\left(P_{a} B^{i}\right)^{\left(B^{t-i}-1\right)}= \\
L_{a} P_{a}\left(B^{t}-1\right)
\end{gathered}
$$

by (A7), (A6), and (A4). We can rewrite (A8) as

$$
L(t)=L_{i} \exp \left(\left(\ln P_{i}\right)\left(B^{t_{i}}-1\right)\right)
$$

Equation (5) of Baranowitz et al. ('77) is:

$$
\frac{d L(t)}{d t}=(\ln B)(\ln P)(L(t))
$$

Introducing the specific growth rate

$$
\mathrm{sgr}=\frac{\mathrm{dL}(\mathrm{t})}{\mathrm{dt}} \cdot \frac{1}{\mathrm{~L}(\mathrm{t})}
$$

we have $\operatorname{sgr}_{i}=1 n$ B In $P_{i}$ from (A10). Hence

$$
P_{i}=\exp \left(\text { sgr }_{i} / \ln B\right)
$$

Thus (A9) is expressible as

$$
L(t)=L_{i} \exp \left(\operatorname{sgr}_{i}\left(B^{t_{i}}-1\right) / \ln B\right)
$$

Equations (A8) and (A13) were found to be particularly convenient for eliciting biological meaning from regressions on regeneration data.

\section{(B) Rationale for weighting least squares}

The following rationale for weighting the least squares was suggested by Mr. Robert Kushler of the University of Michigan Statistical Research Laboratory.

The regression model may be simply expressed as:

$$
\text { 1n } \mathrm{L}=\mathrm{L}_{\mathrm{G}}+\Sigma
$$

where $L$ is the observed length, $L_{G}$ is the pure Gompertz growth, and the error term, $\Sigma$, is the difference between $1 \mathrm{n}$ observed growth (L) and $1 \mathrm{n}$ pure Gompertz growth $\left(\mathrm{L}_{\mathrm{G}}\right) . \Sigma$ may be due to a variety of factors, including measurement error, general health of the animal, diet, etc. Also,

$$
\mathrm{V}(\Sigma)=\mathrm{V}\left(\ln \mathrm{L}-\ln \mathrm{L}_{\mathrm{G}}\right)
$$

We show below that the error variance, $V(\Sigma)$, is proportional to $1 / \mathrm{L}_{G}^{2}$ provided that $\mathrm{V}\left(\mathrm{L}-\mathrm{L}_{\mathrm{G}}\right)$ is about constant. Our aim is the application of weights such that $V(\Sigma)$ will be about constant. Since we don't know $L_{G}$, and since $\mathrm{L}_{\mathrm{G}}$ is assumed only a little different from $\mathrm{L}$, multiplying by $\mathrm{L}^{2}$ will stabilize the variance. Since

$$
\begin{aligned}
\Sigma=\ln L-\ln L_{\mathrm{G}} & =\ln \left(\mathrm{L} / \mathrm{L}_{\mathrm{G}}\right), \text { and } \mathrm{L} / \mathrm{L}_{\mathrm{G}}=1+\frac{\mathrm{L}-\mathrm{L}_{\mathrm{G}}}{\mathrm{L}_{\mathrm{G}}}, \\
\Sigma & =\ln \left(1+\frac{\mathrm{L} \cdot \mathrm{L}_{\mathrm{G}}}{\mathrm{L}_{\mathrm{G}}}\right)
\end{aligned}
$$

It is well known for any "small" positive or negative number $\mathrm{x},\langle\mathrm{x}<<1)$, that $\ln (1+\mathrm{x})$ $\approx \mathrm{x}$. Since $\left(\mathrm{L}-\mathrm{L}_{\mathrm{G}}\right) / \mathrm{I}_{\mathrm{G}}$ may be assumed small,

$$
\Sigma \approx \frac{\mathrm{L}-\mathbf{L}_{\mathrm{G}}}{\mathrm{L}_{\mathrm{G}}}
$$

and

$$
\mathrm{V}(\Sigma) \alpha \mathrm{V}\left(\left(\mathrm{L}-\mathrm{L}_{\mathrm{G}}\right) / \mathrm{L}_{\mathrm{G}}\right)
$$

Factoring out the denominator from the right side of the equation,

$$
\mathrm{V}(\Sigma) \alpha \mathrm{V}\left(\mathrm{L}-\mathrm{L}_{\mathrm{G}}\right) / \mathrm{L}_{\mathrm{G}}^{2}
$$

Now consider whether $\mathrm{V}\left(\mathrm{L}-\mathrm{L}_{\mathrm{G}}\right)$ decreases, remains constant, or increases as the structures we are measuring grow larger. It seems clear that this term does not decrease, since the early (short) regenerate is usually capable of only slight movement, while at later stages it can bend laterally, increasing the measurement error. If we use the same measuring instrument throughout the regeneration period, as was done for Lacerta, and if the tail is readily straightened and remains rather stationary during measurement, as was true for both species, then it seems that the variance should remain about constant for all sizes. If there were more movement in longer regenerates, then the variance would increase. Also, if the magnification of the measurements is decreased for longer regenerates, as was done with the newt tails, then the variance would be expected to increase. Thus it seems probable that $V\left(L-L_{G}\right)$ either remains constant or increases with longer structures. Since we do not presently know which alternative is true, we examine the implications of both. First, consider the case where $\mathrm{V}\left(\mathrm{L}-\mathrm{L}_{\mathrm{G}}\right)$ remains constant. This permits us to rewrite the preceding equation as

$$
\mathrm{V}(\Sigma) \alpha \frac{1}{\mathrm{~L}_{\mathrm{G}}^{2}}
$$

Since we start the procedure possessing only 
the raw data, we must estimate $\mathrm{L}_{\mathrm{G}}$. As $\mathrm{L}_{\mathrm{G}}$ is assumed to be only little different from $\mathrm{L}$, we use the estimate $\mathrm{L}$ for it. So:

$$
\mathrm{V}(\Sigma) \alpha \frac{1}{\mathrm{~L}^{2}}
$$

Thus multiplying the right side of equation (A15) by $\mathrm{L}^{2}$ will stabilize the variance.

Now consider the case where $\mathrm{V}\left(\mathrm{L}-\mathrm{L}_{\mathrm{G}}\right)$ increases with increasing structure size. The purpose of our procedure is to obtain error variances that are constant regardless of the size of the structure. Therefore, if $\mathrm{V}\left(\mathrm{L}-\mathrm{L}_{\mathrm{G}}\right)$ increases, the weighting would have to be decreased (e.g., $L$ raised to a smaller power to compensate).

Unfortunately, precise determination of the trend of the variance with increasing structure size and the factors contributing to the variance is not practical at this time. 